\title{
ON
}

\section{DIRECT WOUNDS OF THE URETER.}

\author{
BY \\ TIMOTHY HOLMES, F.R.C.S., \\ GURGBON TO ST. GRORGR'S HOBPITAL. \\ Received March 2nd-Read April 10th, 1877.
}

The following case is, I think, worthy of the attention of the Society, in connection with a subject which has been little studied in this country, viz. direct wounds of the kidney and ureter. The case, indeed, is not free from ambiguity, which will be fully pointed out in the sequel. The prompt recovery of the patient, fortunately, precluded all possibility of confirming the diagnosis by anatomical examination, and the character of the discharge from the wound was very different from that of healthy urine. Yet I hope to prove to the satisfaction of the surgeons who may think the following case worthy of their attention, that the source of the copious watery discharge which followed the stab in this instance must have been the urinary tract; and that it proves the possibility of a direct and uncomplicated wound of the ureter through the posterior parietes of the abdomen.

CASE.-The patient, Hugh M-, æt. 13, was stabbed by accident by another boy on January 7th, 1877. The 
author of the mischief was running up a staircase after his play-fellow, holding an open clasp-knife in his hand, and half-unconsciously drove the blade into his back. The knife (as was proved by a subsequent examination of the patient's clothes) passed through his jacket, which was a long one, on the left side of the seam, the end of the cut just touching the seam; but it passed through the trowsers on the right of the seam, glancing upwards and outwards, i. e. across and then away from the middle line. It entered the boy's body just on the right of the middle line, and about on the level of the posterior superior spine of the ilium. The wound bled a good deal, and Dr. Forsyth, of Greenwich, was at once sent for, and arrived about half an hour after the injury. The bleeding had then stopped, and Dr. Forsyth was about to apply a compress to the little wound, which was not much above a quarter of an inch long, when he was surprised to find that drops of clear fluid were oozing out of it. Touched with nitrate of silver this fluid gave a white precipitate. The boy was put to bed, and the fluid ran freely from the wound during the whole night. Next day he was suffering from nervous symptoms, viz. faintness, pain in the head, and stiffness of the fingers of both hands. He had occasional vomiting. The respiration was sighing; the pulse 130 . He passed by the urethra during the day, about $20 \mathrm{oz}$. of urine, which was high coloured and contained a large quantity of pink urates, but no blood or albumen.

I saw him the following day (January 9th), in consultation with Dr. Forsyth. He was very much better, had vomited once after food, still complained of slight headache, and the fingers were still a little cramped, but not much. The pulse was 86, and he was quite free from fever, the temperature being only a little above the normal. From the little puncture in the back perfectly clear fluid was still oozing continuously, soaking the bedclothes through the draw-sheet. There was a decided smell of urine in the bed. Dr. Forsyth reported that he 
had passed a probe into the wound for about an inch on the previous day, and that it led in a direction upwards and outwards. This being so, I did not think it desirable to repeat the examination. A sponge, which had been laid beneath the wound, was squeezed out and some of the fluid thus obtained from the wound, as well as some of the urine passed by the urethra, was taken away for examination. As the symptoms were so slight in themselves, and the first effects of the injury were evidently passing over, we felt justified in giving a good prognosis, though we thought it possible that if the fluid were urinous, as we believed it to be, a fistula might remain. We ordered a dranght containing hyoscyamus and bromide of potassium, and advised the friends to persuade the boy to lie on his face as much as possible, but he was too restless to maintain this position for any length of time. We did not think it advisable to make any attempt to close the wound.

It is not necessary to give the daily notes taken by Dr. Forsyth for the next few days. The fluid continued to run out of the wound in immense quantities. It was perfectly impossible to measure the quantity, but it was ascertained that for several days together three large draw-sheets, which were placed under the wound, and which when wet through in one part were shifted to another, were thoroughly soaked in the course of the day with the fluid which ran out of the puncture. Meanwhile his headache and nervous symptoms diminished steadily, and he went on well in all respects.

On the 13th it is noted that the wound had closed externally for a time, and that the bedding was far less wet. On inspection, the closed wound was seen as the apex of a cone, formed by the fluid raising the surrounding tissues. On introducing a probe, about ziv of the confined fluid gushed out to a considerable distance. After this the discharge of the fluid continued as copious as ever till the 20th. He was very restless on the night of the 19th and in a copious perspiration, complaining of 
backache and headache. About 10 a.m. the wound became entirely obstructed, but, on opening it with the pointed end of a probe, a stream was projected to the distance of three inches. Nearly 3 oz. of fluid thus escaped.

The wound finally closed during this night. It was seen to be open and discharging after 11 p.m., but was closed at 6 a.m. He suffered a good deal from headache, and somewhat from vomiting, during this period.

From this time there was nothing to note. I saw him last on January 30th, and heard of him some weeks afterwards perfectly well.

I append notes of the examination of the urine passed by the urethra and of the fluid which ran from the wound, by Dr. Forsyth, and Dr. Ewart, Curator of the Museum of St. George's Hospital, and a single examination of the fluid from the wound by Dr. Ralfe, Lecturer on Physiological Chemistry at St. George's Hospital. I should add that after the first specimen, which was squeezed out of a sponge, the fluid from the wound was obtained quite pure.

First, with regard to the urine passed naturally, Dr. Forsyth noted its quantity from day to day, and found it to vary from $16 \mathrm{oz}$. in the twenty-four hours, on January 11th (the first exact note as to quantity after the accident), to 25 and even $40 \mathrm{oz}$. some days afterwards. On the closing of the wound, the quantity was found to be between 46 and $36 \mathrm{oz}$. The exact statements from day to day of quantity and specific gravity are appended.

Quantities of urine passed by the urethra, with dates and sp. gr.

Sp. gr.

Jan. 11.—そ×vj $\quad \ldots \quad 1030$.

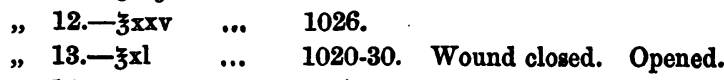

"14.-弓xx $\quad$... 1027-30.

, 15.-Zxxiv $\quad . .1030$.

" 16. - ऊxxx ... 1020. “Inclined to close" (Miss M-'s ex pression at the time), but sheets wetted. Opened. 


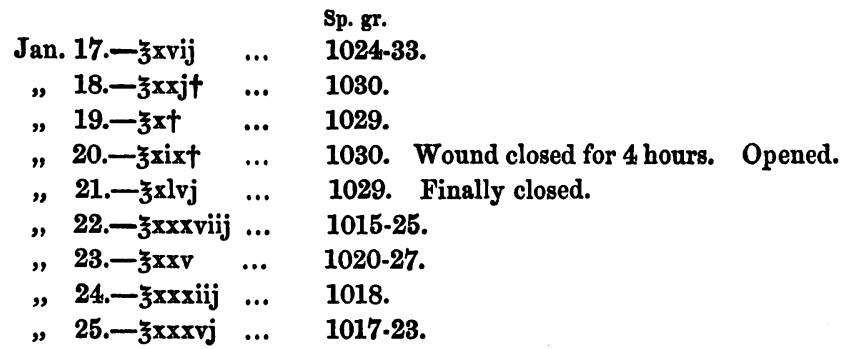

The sign + implies that an unascertained quantity passed with motions, say from $\xi v$ to $̧$ viij. - A. F.

The urine was first noticed to deposit urates on January 9th, the day on which I first saw him, and this deposit continued ever afterwards while the wound was open, and even for some time after its closure, for when I last saw him, on January 30th, there was still a copious deposit of pale urates. No pus or blood was ever noticed in the water, except on the 17th, four days before the final closure of the wound, when a very small quantity of blood was visible to the naked eye, and, as will be seen below, a microscopic trace of blood remained for some time afterwards. The specific gravity (as seen by the appended notes) varied considerably. The first quantity tested after the closure of the wound (January 22nd) had a sp. gr. of only 1015, which is worth noting, and its reaction was very faintly acid. The usual reaction of the urine was decidedly acid, but this varied. Occasionally, though very rarely, it was alkaline.

The following are Dr. Ewart's notes of the examination of fluid from the wound and specimens of urine.

A. Analysis of fluid squeezed from the sponge which lay on the wound January 9 th :

Sp. gr. 1017. Good crystals of nitrate and of oxalate of urea were obtained from it, and a feeble uric acid reaction. There was not enough remaining to test for sugar.

B. Analysis of fluid from the wound, collected quite free from any possibility of foreign admixture: 
Colourless, odourless. Reaction neutral. Sp. gr. 1008. No albumen. Under the microscope no casts, blood, epithelium, or crystals-only bacteria and dirt.

Evaporated to dryness in a water-bath, the fluid left a small residue, non-crystalline, nearly hyaline, devoid of smell. This was taken up with a little distilled water :i. A few drops allowed slowly to evaporate on a microscopic slide gave an abundant crop of chloride of sodium crystals, but no crystals of urea. ii. Another portion was mixed with nitric acid. No nitrate of urea crystals could be detected. iii. The same process with oxalic acid gave a negative result. iv. A fair portion of the residue left after careful evaporation was subjected to the murexide test. No coloration was obtained either with potash or ammonia. v. Sugar was tested for with Fehling's solution. None was found.

The urine of the same day was tested, and found to be of sp. gr. 1030, faintly acid. Colour pale yellow, containing |no albumen, casts, or blood, but an abundance of uric acid crystals and small crystals of oxalate of lime.

Another examination of the fluid from the wound on January 18th gave results identical with that of January 14th.

c. Another comparison of the fluid passed from the wound and of the urine of the same day was made on January 20th :

The fluid from the wound was colourless, odourless, and slightly turbid. Reaction feebly alkaline. Sp. gr. 1008. No albumen. No crystals. Complete absence of organised sediment, except bacteria. The methods described above were again applied, with negative results. No urea, no uric acid, and no sugar were found. Then the experiments were repeated with the following additional precautions. The original residue was treated with absolute alcohol. The residue formed from the alcoholic extract was redissolved in distilled water, and this solution allowed to evaporate slowly in three portions-(1) alone, (2) with nitric acid, (3) with oxalic acid. Nowhere was 
any trace of urea evident. The residue, examined chemically, revealed the presence of abundant chlorides, a small amount of sulphates, and a mere trace of phosphates.

The urine of the same day was of a dark-yellow colour. Sp. gr. 1032, containing a small sediment of blood, and showing a haze of albumen. It contained uric and oxalate of lime, but no casts.

Dr. Ralfe reported with regard to another specimen of the fluid from the wound, ${ }^{1}$ that it was alkaline, containing .08 parts of solid to 9.92 of water ; that the solids consisted of an ordinary albumen, coagulable by heat, and an albumen not so coagulable, but precipitable by acetic acid; that as to fats there was a slight greasy residue from evaporation of the ethereal extract of the dried residue, but no cholesterine; that as to extractives there were traces of urea, .007 in 10 parts, but no uric acid and no glucose; and as to salts there was chloride of sodium $\cdot 005$, and phosphates $\cdot 003$, in 10 parts.

I have been particular in giving the details of this case, inasmuch as I cannot, by search in surgical works or inquiry among my colleagues, find one at all similar to it.

The chief question connected with it is the source of the discharge. There are only, as far as I can see, two possible alternatives. The fluid must either have been urine from a puncture of the ureter, or cerebro-spinal fluid from a puncture of the spinal membranes, through the ligamenta subflava. It seems impossible that the kidney itself could have been wounded; first, because the wound was much too low, considering the length of the knife-blade; and, secondly, because of the absence of any blood in the urine immediately after the injury, or any serious hæmorrhage from the wound. A wound or laceration of the renal substance always, as is well known, gives rise to copious hæmorrhage. Gustar Simon, who has written an interesting treatise on the surgery of the

1 I have not noted when this fluid was obtained, but I believe it to have been subsequent to that last examined by Dr. Ewart. 
kidney, ${ }^{1}$ in which he describes ten cases of wound of that organ, says that hæmaturia is an invariable symptom. And we all know what copious hæmaturia follows on bruises or laceration of the kidney. In this case there was no hæmaturia, except to the most trifling extent, and not till long after the accident. And the appearance at that time of a few drops of blood in the urine is, as I shall point out by-and-bye, confirmatory to some extent of the view which I take of the case, that the ureter was wounded.

I may also dismiss any such wild supposition as that there was some cyst in the lumbar region which had been punctured. There was no trace whatever of any tumour. Nor could a cyst, after having been punctured, have continued to furnish so enormous a flow of perfectly clear fluid for a fortnight.

There remain, then, the two alternatives above mentioned, and though the diagnosis may not be absolutely certain, I submit that it is far more probable that the ureter was the seat of injury.

I place before the Society a preparation to show how easily a knife, made to enter (as in the case of my patient) close to the posterior superior spine of the ilium, can be driven inwards into the spinal canal through the ligamenta subflava, or outwards and upwards through the psoas muscle into the ureter. This preparation was made from the body of a young child. In the body of another child, about the same age as my patient, I drove a narrow knife, as nearly as I could guess, in the direction in which the wound was thought to have run in the case before us. I felt one of the transverse processes as the knife passed in. Having passed a probe along the knife I withdrew the latter, and then, on dissection, found the point of $\mathrm{my}$ probe lying just underneath the peritoneum, within a quarter of an inch of the ureter. The kidney had been previously

1 'Die Chirurgie der Nieren.' Von Dr. Gustav Simon, Prof. d. Chir. in Heidelberg. Stuttgart, 1876. 
removed, but I noted that there was at least an inch of the ureter left above the point of the probe.

We may at once admit, then, the possibility of a wound of the spinal membranes from such an accident, and they are of course nearer the skin than the ureter is, though the latter is, I am sure, fairly within the reach of the knife which caused this accident. But the difficulties in the way of regarding this fluid as cerebro-spinal are, I think, insuperable. In the first place the examination of the child's clothes, and Dr. Forsyth's examination of the wound, render it nearly certain that the knife was directed outwards and upwards, while in order to reach the spinal membranes it must have passed inwards. Then, how can we conceive that the membranes could be laid open, yet none of the cords of the cauda equina be injured (which in this case they assuredly were not), nor any symptoms of spinal inflammation follow, during the whole fortnight that the wound remained open ? Again, could the cerebro-spinal fluid be secreted in sufficient quantity to furnish this enormous flow. I speak on this point with some diffidence. I once assisted Mr. Athol Johnstone to remove a congenital tumour formed in the interior of the spinal canal in the sacral region, the laminæ being unossified. On the removal of the tumour the membranes were fally exposed, and. we saw them exhibit the same movements, synchronous with respiration, which the cranial dura mater is so often seen to present. ${ }^{1}$ That case proves that there is a considerablo quantity of cerebro-spinal fluid at the end of the canal. But here, the flow was so instantaneous, so equable, and so continuous, that it seemed as if it could only come from a perennial source of supply like the kidney. For surely the spinal membranes, if called upon at once for something so much beyond their usual quantity of secretion, even allowing that they could respond to the call (which is doubtful), must have exhibited some sign of the

1 The case and dissection will be found in 'Path. Soc. Trans.,' vol. viii, pp. 16, 28.

VOL. LX. 
irritation by which alone they could have been so stimulated. But in this case there were absolutely no signs of irritation or inflammation of any of the spinal structures. It is true that the child suffered from headache, and that occasionally for the first few days after the accident his fingers were a little stiff; but both those symptoms were too trivial in themselves to be symptomatic of any grave injury, especially they could not be connected with injury in the lumbo-sacral region, and similar nervous symptoms had been noticed in this boy by Dr. Forsyth in previous illnesses.

In regard to the quantity and composition of the cerebro-spinal fluid Magendie is quoted by Hirschfeld and Léveillé, as estimating it in a man of middle height at 62 grammes $=2 \frac{1}{4}$ oz. about, though he adds that in spinal atrophy the quantity may be six times as great. In 'Quain's Anatomy' the quantity is given conjecturally after Majendie as varying from 2 drachms to 2 ounces. So that we may probably take about 2 ounces as a fair average. The composition is thus given in Hirschfeld :

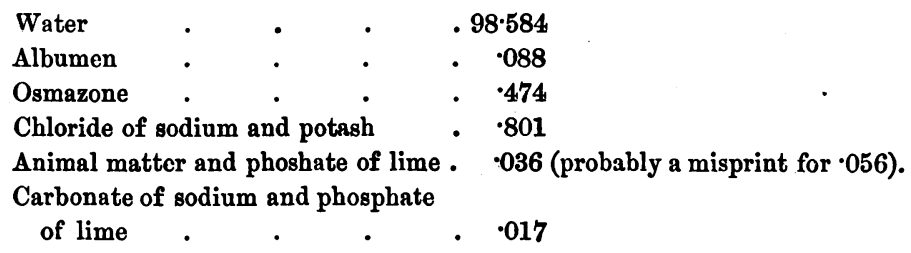

Other observers, I believe, regard glucose as a constant component of this fluid.

It is added in Hirschfeld, "Surgical cases [by which I presume fractures of the base of the skull are intended] show that this liquid is rapidly resecreted, but its loss in considerable quantities always oauses death."

It seems, then, from the notes given at pages $253-255$, that the composition of the fluid from this wound, though, no doubt, much nearer that of the cerebro-spinal

1 'Traité du Système Nerveux,' 1866, p. 21.

2 'Quain's Anatomy,' eighth edition, vol. ii, p. 575. 
fluid than of healthy urine, yet differs in specific gravity, in minute composition, and in the absence of glucose. I may add, on Dr. Ralfe's authority, that the precipitate caused by acetic acid in this fluid was probably mucin, and that this strengthens the view that the fluid was derived from the urinary passages. And, still more, the enormous and continuous flow of liquid from the wound, far from inducing death, as Hirschfeld says it would if cerebro-spinal, gave rise to no symptoms whatever. The only difficulty in regarding the wound as situated in the ureter was the character of the fluid. It is, I allow, somewhat surprising that so very small a puncture should have remained freely open, considering the mass of muscles and fasciæ through which the knife must have passed to reach the ureter; but nearly the same difficulty exists in the case of the spinal membranes, which are covered by all the mass of fasciø and muscles lying in the vertebral gutter. The perpendicular course of the muscular fibres furnishes, I suppose, in either case, a reason why a small wound may remain open. If such a stab were to reach the ureter, that tube would be found full of fluid; its vermicular contraction would expel the fluid in drops, so long as no obstruction existed, and in a stream whenever the flow had been temporarily barred, just as happened in this case, and the flow would be permanent, even in the absence of any irritation, just as this was. None of these characters would be present in a wound of the spinal membranes. The composition of the fluid, however, which Dr. Ralfe's and Dr. Ewart's analyses show, does certainly render this explanation of the case difficult. It is true that Dr. Ewart's examination of the first specimen of urine did give some urinous reaction, but only to a microscopical extent, and only such as might easily have come from an accidental contamination (with urine) of the sponge from which that fluid was squeezed. And it was ascertained that the sponge in question had actually fallen into the chamber-pot a month previously. It had, however, been carefully scalded 
afterwards, and had been in use as a washing-sponge during the whole of the intervening time; so that it was hardly likely that any urine could still remain in it. At the time when this fluid was collected (when I visited the boy) the urinary smell was quite perceptible in the bed, though hardly so strong as it would have been from so copious a flow of normal urine. After this time, however, no urinary constituents whatever were detected in the fluid, with the dubious exception of the very small quantity of urea in the specimen analysed by Dr. Ralfe, a quantity, however, which was in Dr. Ralfe's judgment inconsistent with the idea that the fluid was cerebro-spinal. The want of colour in the fluid is also a very remarkable circumstance if it is looked on as urine from the ureter.

The dubious composition of the fluid has been, however, noted by Mr. Stanley in the second of his two cases of ruptured ureter, related in the 'Med.-Chir. Trans.,' vol. xxvii. The patient was under Mr. Vincent's care. $\mathrm{Mr}$. Stanley says (page 10), "The fluid obtained from the abdomen was found to be albuminous, and to contain a small quantity of urea, but from the indistinct recognition of the healthy urinary salts in it a high chemical authority pronounced it not to be urine." In this case, the source of the fluid from the pelvis of the kidney was proved by dissection. I may just observe that in the other case given by Mr. Stanley (which was under his own care) the sp. gr. of the fluid was the same as in the fluid tested by Dr. Ewart, viz. 1008 (see page 254). Here, however, the constituents of the urine were perfectly recognisable. Both in Stanley's and Vincent's cases the colour was yellow.

That the secretion from the kidney may in abnormal states approach in composition to that of the fluid in this case is well known. Thus, in Dr. Day's translation of 'Simon's Chemistry,' vol. ii, page 234, there are some analyses of watery urine in nephritis, quoted from Becquerel, in which the quantity of solids was almost as low as in this instance, and in the chapter on hydruria or 
polyuria in the same volume (pp. 305, 306), there are some cases still more in point, though the details are not sufficiently exact. Thus, in a man under the care of a physician named Stosch, it is said that the urine (passed in large quantity, four to six quarts daily) " contained no sugar, and scarcely a trace of urea or of the other ordinary constituents of urine," words which are almost exactly applicable to our case.

A confirmation of the diagnosis is afforded by the condition of the urine passed by the urethra after the injury. We may assume that it was normal before the accident, as the child was in perfect health. As soon as it was examined after the injury it was found to be in very diminished quantity, and soon began to contain a very large quantity of lithates. After the first closure of the wound (on January 13th) the urine recovered its normal volume, fell again when the wound was reopened, rose again at the second closure of the wound, and recovered its natural quantity as soon as the wound had permanently healed.

At one time, shortly before the healing of the wound, a little blood appeared in it, a very natural result of any slight movement of the body while the granulations of the wound were in close proximity to the opening in the ureter, but a phenomenon quite inexplicable on the hypothesis of a wound of the spinal membranes.

If it could be shown that a wound of the ureter or a lesion of that organ could suspend the true secreting function of the corresponding kidney, while it left its percolating function intact, or even if any theoretical explanation of such a result could be given, the case would be quite clear, since the opposite kidney would have double secretive work to do, and the urine passed by the urethra would be scanty, with excess of lithates, \&c. It is true that Stanley's cases go some way towards showing the possibility of this, but they can hardly be regarded as decisive, and in them, as the fluid was extravasated into the tissues and retained there for a 
considerable length of time before it was drawn off, its composition (even if it had been more accurately ascertained than it was) might have been expected to differ from what it would have been if it had escaped directly out of a wound.

Lesion of the nerves of the kidney produces watery urine. "Section of the renal nerves," says Dr. Michael Foster," "is followed by a most copious secretion-by what has been called hydruria or polyuria, the urine at the same time frequently becoming albuminous.", This refers, however, of course, to the section of the nerves above the kidney, while here the lesion, whatever it was, must have been below that organ.

Very little attention has, I think, been paid to the diagnosis of direct wounds of the ureter. Gustar Simon, in the work above referred to, mentions no case in which the ureter was directly wounded, nor does he seem to contemplate the possibility of such an injury. In fact, if we consider the great depth at which the tube lies, its small size, and its close proximity to the peritoneum, we can easily understand that an uncomplicated wound of the ureter must be among the rarest of surgical injuries. Such, however, I believe, to have been the lesion in the case before us, and though I am sensible that there is always something unsatisfactory in the record of a case, the diagnosis of which is not absolutely certain, yet $I$ thought the one here narrated, whatever view may be taken of it, was too extraordinary to be allowed to remain unrecorded. I hope that, by making it public, I may elicit some information from others, which may clear up its obscurities, or that at any rate it may be of use hereafter when some parallel case may occur, in which the nature of the injury can be verified anatomically.

Note.-Mr. Morris has been so kind as to send me the

1 'Textbook of Physiology,' p. 279.

2 Hermann also gives similar though vaguer statements, 'Phys., translated by Gamgee,' pp. 115, 117. 
following conjectural explanation of the peculiar nature of the discharge in this case, assuming that the ureter was really wounded.

"May it not have been that the ureter was a dilated one, from some congenital obstruction which had later on become removed, yet not before the kidney had been so far impaired as no longer to be able to separate the usual amount of solids? Such is the case in hydronephrosis, as I mentioned in a paper published in the 'Med.-Chir. Trans.' of last year, pages 253 and 254. This supposition explains both the liability to injury of the ureter and the characters of the urine, while we know that dilated ureter from congenital, as well as from non-congenital causes, is far from uncommon."

This explanation is certainly very ingenious, and is to my mind a probable one, and I have noticed that a similar idea was propounded in a discussion on the case, which was published in a foreign journal, to which, however, I have mislaid the reference. I must leave the matter to the reader's judgment.

I have not discussed the possibility that the fluid might have come from the peritoneal cavity. The immediate escape of a large quantity of fluid, and the absence of albumen, seem to me conclusive against any such explanation of the above case. 